\title{
DIVERSIDAD Y RACISMO EN AMÉRICA LATINA
}

Sofía Reding*

No hay odio de razas, porque no hay razas. Los pensadores canijos, los pensadores de lámparas, enhebran y recalientan las razas de librería, que el viajero justo y el observador cordial buscan en vano en la justicia de la naturaleza, donde resalta, en el amor victorioso y el apetito turbulento, la identidad universal del hombre. José Martí

RESUMEN: En este texto se presenta un análisis crítico del racismo, como práctica discriminatoria recurrente en Brasil, Ecuador y Perú, heredada de la Colonia y refuncionalizada en los estados contemporáneos.

PalABRAS ClaVe: Discriminación, Racismo, Estados contemporáneos.

ABSTRAC: In this text is presented a critical analysis of the racism, as discriminatory recurrent practice in Brazil, Ecuador and Peru, inherited from the Colony and still functional in the contemporary states.

KEY WORDS: Discrimination, Racism, Contemporary States.

En América Latina siempre resulta muy complicado tratar el tema del racismo, especialmente porque suponemos que, desde la abolición de las castas y de la esclavitud, se ha superado todo aquello que impedía la concreción de una democracia incluyente. Y sin embargo, incluso a pesar de haber establecido leyes contra la discriminación, éstas no han podido

* Departamento de Humanidades. Tecnológico de Monterrey, campus Ciudad de México (reding@itesm.mx). 
resolver el problema del racismo, en buena medida porque el sistema de castas permanece en el imaginario latinoamericano porque legitima tanto la subordinación como la hegemonía. Desde luego, las argumentaciones racistas, inseparables del discurso clasista, están bien escondidas en nuestro imaginario: desde el inicio de la Colonia se han presentado los caracteres físicos de las personas como forzosa e inevitablemente ligados a determinados estratos sociales, lo que evidentemente no es más que un artificio. A partir del momento en que se asegura que existen culturas inferiores y que además hay una correspondencia entre raza y cultura, comienza la segregación. Desde luego, no hay relación alguna entre razas y culturas, pues todos los homines evolucionaron de la misma forma independientemente de la "raza" y desarrollaron formas culturales distintas; pero puesto que algunas fueron acomodadas por los evolucionistas del siglo XIX en posiciones inferiores a la europea, el control que se ejerce sobre los llamados "pueblos inferiores" o grupos dominados aparece como si estuviera justificado. Sobre ese punto escribió Aguirre Beltrán:

El evolucionismo social no tiene el respaldo objetivo, la evidencia incontrovertible de hechos comprobables que otorgan validez y fortaleza al evolucionismo natural. El hombre no tiene programada su existencia a la manera genéticamente determinada, que gobierna la conducta animal. La facultad de crear cultura, de transmitir mediante la enseñanza y aprendizaje la experiencia acumulada en la historia del género humano, hace insostenible la transferencia y extrapolación de las hipótesis biológicas al ámbito cultural, tal y como pretende hacerlo, sin empacho alguno, el darwinismo social. El evolucionismo sitúa a la civilización europea como la coronación del desarrollo humano y es, consecuentemente, etnocéntrico y proclive a levantar formas irracionales de racismo. ${ }^{1}$

Así pues, el racismo es mucho más que una actitud individual; se trata de un intento por justificar institucionalmente que cierto fenotipo es seña de inferioridad. De ello derivan actitudes discriminatorias en grupos

${ }^{1}$ Gonzalo Aguirre Beltrán, Lenguas vernáculas, México, Ediciones de la Casa Chata, 1983 , p. 140 
en los cuales se reflejan altos niveles de un insano etnocentrismo, así como también conductas xenofóbicas y mixofóbicas. El prejuicio racial no es sólo exhibido sino justificado cuando se apela a supuestas experiencias históricas o personales para legitimar la antipatía racial, volviendo la actitud racista en "coherente" con un sistema dado. No hay actor sin un sistema de acción, sin relaciones sociales o intersocietales que permitan el surgimiento de personalidades racistas y que contextualizan la conciencia o subjetividad, como lo afirma Wieviorka. ${ }^{2}$ Aunque todos los grupos humanos son etnocéntricos por necesidad, no todos se permiten ser racistas. El origen del racismo no es exclusivamente el etnocentrismo en general, sino una de sus modalidades, la menos sana, ya que mientras el etnocentrismo es universal, el racismo es sólo promovido por ciertas estructuras sociales que encuentran en el etnocentrismo, esto es, en un espectacular desarrollo de fuerzas centrípetas al interior de un grupo social, la justificación para su conducta racista y su fobia por la alteridad. Conviene por ello apelar a una definición de racismo para diferenciarlo del etnocentrismo:

Racismo es todo conjunto de creencias en que las diferencias orgánicas, transmitidas por la vía genética (reales o imaginarias) entre los grupos humanos, están intrínsecamente asociadas con la presencia o ausencia de ciertas capacidades o características de gran importancia social y, por lo tanto, en que tales diferencias son una base legítima para establecer distinciones injustas entre los grupos definidos socialmente como razas [...] La existencia de razas en una sociedad determinada presupone la presencia del racismo, pues sin racismo toda característica física queda carente de significado social. No es la presencia de diferencias físicas objetivas entre los grupos lo que crea las razas, sino la aceptación social de tales diferencias como socialmente importantes o pertinentes. ${ }^{3}$

Como podemos observar, el racismo aparece vinculado a determinado proyecto social y eso explica por qué ciertas personas adquieren prejuicios raciales y otras no. Según Adorno y su equipo, se debe a lo que

\footnotetext{
${ }^{2}$ Michel Wieviorka, El espacio del racismo, Barcelona, Paidós, 1992, p. 74.

${ }^{3}$ Pierre van den Berghe, Problemas raciales, México, FCE, 1971, p. 29.
} 
explicaron en su teoría de la frustración/agresión y de la personalidad autoritaria. ${ }^{4}$ El argumento base de esta teoría es en pocas palabras el que sigue: la frustración producida en ciertos individuos se desplaza del agente causal de la frustración a un chivo expiatorio, ${ }^{5}$ que a pesar de ser ajeno a la situación en cuestión, pasa a ser víctima de una agresión:

El phármakos era, por un lado, un ser humano que tenía funciones similares a las de un "chivo expiatorio"; sobre él recaían todas las agresiones y violencias del pueblo, liberando a éste de ellas; y una vez que el phármakos se hacía depositario de estas cargas negativas, se le sacrificaba con el exilio o la muerte (generalmente por lapidación), y al mismo tiempo se le sacralizaba, haciéndosele objeto de veneración. El phármakos era así objeto de maldad y al mismo tiempo de salvación. ${ }^{6}$

Si analizamos la realidad latinoamericana, nos daremos cuenta que las minorías han sido culpadas del atraso y la pobreza que se vive en el subcontinente. Las incongruencias que se alojan en el seno de los discursos nacionalistas — que suelen promover obsesivamente el mestizaje o la franca eliminación de la diversidad cultural—, dan cuenta de una forma más compleja de racismo: el racismo cultural. Esta nueva forma de racismo no se inspira en razones genéticas —o no sólo en ellassino en la presunción de que ciertos rasgos temperamentales son inseparables de la idiosincrasia de un grupo humano, lo que permite una jerarquización social capaz de destruir la igualdad supuestamente garantizada por el Estado. En Perú, por ejemplo, es común el "líbreme Dios de cholo con mando, de negro con plata y de blanco calato", mientras que un proverbio brasileño asegura que "el dinero blanquea". Pero a los "blancos honorarios", Fanon les dice: "Mi piel negra no es depositaria de valores

\footnotetext{
${ }^{4}$ Véase Theodor Adorno, Frenkel-Brunswick, Levinson y Standford, The authoritarian personality, Nueva York, Norton, 1953.

${ }^{5}$ Véase Levítico, 16, 20-22.

${ }^{6}$ Juliana González, El Ethos, destino del hombre, México, UNAM/FCE, 1996, p. 87.
} 
específicos [...] No tengo derecho, yo como hombre de color, de buscar en qué mi raza es superior o inferior a otra raza". ${ }^{7}$ En el fondo, asegura Fanon, el problema no es sólo de Próspero - el dominador - , sino que atañe también a Calibán —el dominado—, porque parece estar más preocupado en elegir un amo que en alcanzar la libertad y hacerse cargo de su destino. Eso resulta, en verdad, irracional. El racismo es patológico, neurotizante, angustiante: provoca conductas desviadas como el etnocidio o genocidio. Como dice Fanon: "Para un hombre cuya única arma es la razón, no hay nada más neurotizante que lo irracional". ${ }^{8}$

Sin duda, remover el espinoso tema del racismo suscita enormes molestias porque llama al autocuestionamiento y autocrítica; parece como si el problema en cuestión hubiese sido superado ya desde hace mucho tiempo y que la carga emocional - la culpabilidad - se hubiera esfumado. Pero sabemos que el racismo es el resultado de la discriminación practicada por regímenes autoritarios ejercidos por determinada clase a la que se identifica con algunos rasgos físicos y un significado cultural (notablemente los caracteres de blancos europeos), y que presenta como justificado el dominio despótico de unos sobre otros. Basta echar un vistazo a las imágenes que de lo latinoamericano difunden los medios masivos de comunicación, particularmente en épocas de crisis generalizadas, para darnos cuenta de que el racismo se infiltra en los proyectos nacionales de los estados latinoamericanos que buscan identidades fijas y que las publicitan profusamente por todos los medios disponibles. En el caso de Perú, por ejemplo, la publicidad maneja tipos raciales más bien criollos cuando se trata de vender productos electrodomésticos, paquetes turísticos o automóviles, pero cuando se publicitan rifas, sorteos y loterías nacionales, todos (negros, indios, zambos, mestizos, cholos, blancos, japoneses o chinos) son bienvenidos. También en Brasil la publicidad suele apelar a los diversos tipos raciales cuando

\footnotetext{
${ }^{7}$ Frantz Fanon, Piel negra, máscaras blancas, Buenos Aires, Shapire, 1974, p. 201.

${ }^{8}$ Ibid., p. 109.
} 
así conviene — “nuestros japoneses brasileros son mejores... compre Sony hecho en Brasil"-. ${ }^{9}$

En Brasil la ascendencia realiza un papel intrascendente en el establecimiento racial, ya que se pueden utilizar más de cuarenta categorías raciales, existiendo cientos de términos raciales originados en combinaciones de aquéllas. Según Marshall, los atributos fenotípicos entran en las clasificaciones, pero ninguna combinación es predictiva de la raza, puesto que la posición socioeconómica constituye un determinante importante del estatus racial. La división étnica se ha pensado según categorías que manifiestan las maneras en que los segmentos de una población se relacionan con segmentos del mercado de trabajo. ${ }^{10}$ Aunque el modelo de segregación étnica urbana más conocido y más estudiado es el de las ciudades norteamericanas, esta segregación se puede observar, aunque no tan marcadamente, en otras ciudades. En las brasileñas, por mucho que se trate de una sociedad multirracial, los negros y mulatos ocupan los niveles más bajos de la escala social. Inclusive si las minorías étnicas también están espacialmente segregadas, tanto entre las regiones del país como al interior de las áreas metropolitanas, el índice de disimilaridad, el cual mide la segregación urbana, es muy inferior al de las áreas metropolitanas norteamericanas. Así pues, dos sociedades con un pasado igualmente esclavista — la brasileña y la norteamericana- han evolucionado hacia patrones distintos de segregación espacial y discriminación racial, en función de factores culturales, institucionales y económicos que favorecieron la mezcla de razas y la integración social. Las oportunidades de la población afro-brasileña son muy limitadas a la hora

${ }^{9}$ Hay que recordar, con relación al racismo mediático que: "los medios de comunicación contribuyen a definir la situación étnica por medio de sus propias estrategias de discurso". De hecho, "los medios de comunicación principales en el mundo occidental han seguido en parte el movimiento de la élite y las formas populares de resentimiento contra el otro, y hasta las han exacerbado". Teun van Dijk, Racismo y análisis crítico del discurso, Barcelona, Paidós, 1997, pp. 176 y 241.

${ }^{10}$ Gloria Marshall, "Clasificaciones raciales populares y científicas”, en Dobzhansky et al., Ciencia y concepto de raza (genética y conducta), Barcelona, Fontanella, 1972, p. 169. 
de lograr una representación en el Congreso, educación, salud, empleo y en general todo lo necesario a la vida, porque el racismo sigue en pie:

As atuais classes dominantes brasileiras, feitas de filhos e netos dos antigos senhores de escravos, guardam, diante do negro, a mesma atitude de desprezo vil. Para seus pais, o negro escravo, o forro, bem como o mulato, eram mera força energética, como um saco de carvão, que desgastado era substituído facilmente por outro que se comprava. Para seus descendentes, o negro livre, o mulato e branco pobre são também o que há de mais reles, pela preguiça, pela ignorancia, pela criminalidade inatas e ineluráveis. Todos eles são tidos consensualmente como culpados de suas própias desgraças, explicadas como características da raça e não como resultado da escravidão e da opressão. Esta visão deformada e assimilada tambén pelos mulatos e até negros que conseguem ascender socialmente, os quais se somam ao contingente branco para discriminar o negro-massa. ${ }^{11}$

Así pues, en Brasil prevalecería la expectativa de que el país se tornara blanco como si eso fuera garantía para el acceso a los bienes. Esto es más relevante cuando se considera que la mayor parte de la población negra es pobre y que, a pesar de que su identidad en muchas ocasiones, en el medio rural, pasa por la relación con la tierra, no tienen acceso a ella, o bien, en el medio urbano como es el caso de las favelas, carecen de la posibilidad de ser propietarios de su morada, considerando la forma en que fue adquirida y el terreno sobre el cual se construyó. Fomentar el odio entre las razas es sencillo cuando se promueve el clasismo. Las prácticas racistas por supuesto vienen a estar ligadas con la propia situación económica del país en el que se promueven. Como en toda América Latina, la dependencia de Brasil respecto al extranjero es clara. Y también ahí se ha creído, como en otros sitios, que es necesario añadir al doloroso ajuste económico, un ajuste de tipo cultural: la mente colonizada tiende a culpabilizarse de sus fracasos económicos, como si éstos

${ }^{11}$ Darcy Ribeiro, "Ser negro”, CARTA 'Falas, reflexões, memórias, núm. 13, Gabinete do Senador Darcy Ribeiro, Brasilia, abril, 1994, p. 14. 
tuvieran un origen cultural. Por un lado, dice Garcia dos Santos, estaría un capitalismo real cuyos efectos, como la pobreza y extrema pobreza, son criticados por el atraso que implican. Pero por el otro lado, se fantasea con una sociedad capitalista ideal, inalcanzable y avanzada: "El efecto disruptivo se convierte en un impedimento subjetivo que solamente se podría vencer a través de la adhesión al sistema". ${ }^{12}$

Adherirse al sistema, se suele decir, implica forzosamente el mestizaje. ¿Qué ocurrió con la población negra de Brasil? Ribeiro calcula que la población africana introducida al Brasil oscila alrededor de unos 10 millones de personas. Traídos principalmente de la costa occidental africana, los negros no pertenecían a los mismos grupos. A partir de la abolición, la población creció de manera notoria, pero la confusión tan típicamente brasileña entre condición social y color fomentó el mestizaje. ${ }^{13}$ Como tan acertadamente señala Ribeiro, esta expectativa de hacer desaparecer al negro por medio del mestizaje, también es una forma de racismo, frente a lo cual ha habido respuestas que son como islas en el mar del mestizaje. ${ }^{14}$ Los resultados pueden ser desastrosos en el sentido de una pérdida de identidad y de la capacidad de organizar una estructura socio-cultural, puesto que no hay un territorio propio en el cual se puedan reproducir los bienes materiales y espirituales.

En cuanto al caso colombiano, las conductas racistas de blancos hacia negros son terribles, aunque también es cierto que el racismo es más crudo cuando los chivos expiatorios son los indios. Sin embargo, todas las situaciones discriminatorias y los prejuicios raciales de la sociedad colombiana actual se enraizan en una injusticia histórica, pues hasta ahora no se ha hecho nada para asegurar a los descendientes de esclavos ningún derecho de propiedad sobre el patrimonio nacional que

${ }^{12}$ Laymert Garcia Dos Santos, “Tecnología, naturaleza y el 'redescubrimiento' de Brasil”, en Biodiversidad y derechos de los pueblos. Amazonia por la vida, Quito, Acción Ecológica, 1996, p. 30.

${ }^{13}$ Darcy Ribeiro, O povo brasileiro: a formazão e o sentido do Brasil, São Paulo, Companhia das Letras, 1995, p. 184.

${ }^{14}$ Ribeiro, "Ser negro...”, p. 16. 
contribuyeron a forjar en más de cuatro siglos y medio. ${ }^{15}$ Está claro que el racismo es producto de un hecho histórico común a nuestros países: el colonialismo. De ahí, por ejemplo, que en la configuración de la sociedad, y en especial de la urbe, el imaginario colonial permanezca relativamente vivo y el sistema de castas se refuncionalice. Es conveniente recordar lo dicho por Walzer para entender la especie de satanización de la que son objeto quienes no forman parte de las burocracias blancas:

Nosotros entendemos a las castas como grupos rígidamente segregados, y al sistema de castas como una "sociedad plural", como un mundo de fronteras. Pero el sistema es constituido por una extraordinaria integración de significados. Prestigio, riqueza, conocimiento, cargo, ocupación, alimentación, vestido e incluso el bien social de la conversación: todos están sujetos a la disciplina lo mismo intelectual que física de las jerarquías. Y la jerarquía misma es determinada por el valor único de la pureza racial. ${ }^{16}$

Ahora bien, si pensamos que la sustitución del término biologicista de raza por el de etnia (que eventualmente incluiría criterios raciales) puede solucionar el problema, estaremos equivocados. Como recuerda Callirgos en todo caso habría que pensar en las nociones de raza social y etnia como resultados de un proceso de construcción de la subjetividad. ${ }^{17}$ De hecho, para Caso: "Es indio todo individuo que se siente pertenecer a una comunidad; indígena que se concibe a sí mismo como indígena porque esta conciencia de grupo no puede existir sino cuando se acepta totalmente la cultura del grupo; cuando se tienen los mismos ideales éticos, estáticos, sociales y políticos del grupo; cuando se participa en las simpatías y antipatías colectivas". ${ }^{18}$ La imagen que un grupo humano tiene acerca de lo que es "raza" depende de cómo este grupo se ha definido socialmente,

${ }^{15}$ Manuel Zapata Olivella, Las claves mágicas de América, Bogotá, Plaza \& Janés, 1989, p. 174.

${ }^{16}$ Michael Walzer, Las esferas de la justicia: una defensa del pluralismo y la igualdad, México, FCE, 1997, pp. 39-40.

${ }^{17}$ Juan Carlos Callirgos, El racismo: la cuestión del otro (y de uno), Lima, Centro de Estudios y Promoción del Desarrollo, 1993, pp. 49-50.

${ }^{18}$ Alfonso Caso, Indigenismo, México, INI, 1958, p. 14. 
porque en ocasiones los criterios pueden depender de ciertas características físicas que "emparentan" a las personas. Es lo que hacen por ejemplo los kunas de Panamá y Colombia, quienes utilizan el tipo sanguíneo (fenotipo $\mathrm{O}$, rhésus positivo) como uno de los parámetros que definen su pertenencia al grupo. De todas formas, aunque las características consideradas pueden coincidir muy aproximadamente con las étnicas, la definición social del grupo puede ser cultural y no racial. Por eso Bastide prefiere dejar de lado la noción de raza en su sentido biologicista y define la noción de raza social así: "Aquellos grupos, internos o externos, respecto de una comunidad, de los cuales se presume que poseen atributos biológicos comunes o un origen genético diferente, pero cuya extensión varía de un lugar a otro, lo que cabalmente pone de relieve el carácter sociológico y no biológico del grupo". ${ }^{19}$ Ciertas prácticas afro-americanas pueden ilustrar esto que hemos dicho. En el caso de los afro-brasileños, es obvio que éstos no pertenecen a un grupo étnico en particular, debido al origen heterogéneo de sus antepasados y al grado de mestizaje ${ }^{20}$ o que se ubiquen en una clase social en especial, pero han hecho de la raza una construcción socio-cultural que en nada se asemeja a la noción biológica clásica. En gran medida, el Movimiento Negro en Brasil fue inspirado por la lucha de liberación de los pueblos africanos y de la población negra norteamericana, cuyos lemas iban desde el puño erguido del Black Power hasta la Affirmative Action que se traduce en políticas de cupo o subvenciones, pasando por una producción cultural impresionante. Sin embargo, al alentar ciertas ilusiones sobre el vigor y la creatividad de la propia raza, la negritud terminó por circunscribirse al ámbito cultural y desdeñó, finalmente, la posibilidad de organizar a los negros para las luchas reivindicatorias, ocupándose de batallas meramente simbólicas, y llamando a la población negra a unirse por lazos de raza y no por los de clase, reduciendo así su combatividad. En el caso de las Antillas la respuesta al racismo fue el movimiento de la Negri-

${ }^{19}$ Roger Bastide, El prójimo y el extraño. El encuentro de las civilizaciones, Buenos Aires, Amorrortu, 1975, p. 34.

${ }^{20}$ Hay tres grandes grupos de esta población: las culturas sudanesas, culturas islamizadas y culturas bantú. Véase Ribeiro, O povo brasileiro..., p. 114. 
tud. Éste, que es un movimiento cultural cuyo origen puede ubicarse en los Cahiers d'un retour au pays natal, de Aimé Césaire (1956), exaltaba la piel porque es la piel la que en el imaginario del colonialismo racial tanto se desprecia. Esto es lo que hizo decir a Sartre que:

En realidad la negritud aparece como un paso de un avance dialéctico: la tesis es la afirmación teórica y práctica de la superioridad blanca; la antítesis, representada por la posición de la negritud, es el momento de la negatividad. Pero este momento negativo no se da abasto [...] prepara tendencialmente la síntesis o la realización de lo humano en una sociedad sin razas. La negritud existe, pues, para autodestruirse, es un medio y no un fin. ${ }^{21}$

Con todo, para Ribeiro es posible una democracia racial sólo si se da conjuntamente con una democracia social; sin ella, la democracia racial no será más que un mito. ${ }^{22}$ Para Zapata Olivella todas las teorías del blanqueamiento para borrar o disimular la presencia negra en nuestro continente tienen su origen o están sospechosamente emparentadas con las ideas y prácticas racistas de Estados Unidos. Las políticas discriminatorias contra el negro — compulsión a la miseria y el confinamiento, negación de sus derechos humanos y cívicos, pagos de salarios irrisorios y linchamientos - ligadas a la segregación, en vez de atenuar el abismo contribuyeron a tornar más virulento y explosivo el conflicto. La década de los sesenta no fue sino la primera llamada de atención a los racistas para hacerles ver que sus políticas segregacionistas los destruirían a la postre. Así nacieron los reclamos ya no de igualdad de derechos civiles de blancos y negros, sino de participación directa, activa y autónoma de la población afro-americana en la dirección del Estado. ${ }^{23}$

${ }^{21}$ Jean Paul Sartre, “Orphée noir”, en Situations III, París, 1949, p. 208.

${ }^{22}$ Ribeiro, "Ser negro”..., pp. 17-18. Es útil recordar que en la Constitución de 1988 se declaró al racismo como una conducta criminal. El texto constitucional se propone erradicar la pobreza y la marginación y reducir las desigualdades sociales y regionales, así como promover el bien común independientemente de prejuicios de cualquier índole.

${ }^{23}$ Zapata Olivella, Las claves mágicas de América ..., pp. 89-90. 
Otro de los autores que trata el tema del blanqueamiento es Hurbon. ${ }^{24}$ Para este sociólogo, hay un conjunto de discursos que han representado a Haití como el "país del vudú", en el que hechicería, "zombificación" y canibalismo han sido utilizados para crear y fomentar prejuicios contra la población negra. ${ }^{25} \mathrm{El}$ imaginario occidental, al decir de Hurbon, ha podido recrear suficientes imágenes sobre el "otro" en las que no se percibe aún una ruptura decisiva. En realidad, lo que a Hurbon le interesa es ir más allá del paradigma bárbaro/civilizado y estudiar el proceso al que ha llevado el afán por "barbarizar al bárbaro" y que se apoya en el exterminio potencial o efectivo de toda otredad. $\mathrm{Su}$ investigación consiste en estudiar y analizar el modo en que se ha producido o imaginado al bárbaro, hoy disipado en las abstractas generalidades sobre la otredad y la diferencia. Su propósito es "buscar los sucesivos rostros que adopta el bárbaro, desde la esclavitud hasta nuestros días, a través de discursos y relatos sobre el canibalismo, la hechicería y la 'zombificación', ese extraño halo constituido en torno al vudú y a cuyo exorcismo se ha entregado la élite haitiana". ${ }^{26}$ Patrimonio cultural de la mayoría haitiana, el vudú es un culto satanizado por el catolicismo y, según las leyes, un delito. Antes de la llegada al poder de Duvalier en 1957, que utilizó el vudú para legitimar una presidencia vitalicia hereditaria, el presidente Élie Lescot, en una campaña denominada de los "Rechazados", pretendió que cada haitiano pronunciase en la iglesia el juramento de rechazar definitivamente toda práctica y creencia vudúes. ${ }^{27}$ Así, las prácticas culturales se convierten en pecados y delitos que hay que suprimir para que se tengan, no ciudadanos, sino campesinos liberados de los hechiceros, dispuestos a servir como zombis al nuevo amo.

${ }^{24}$ Véase Sofía Reding Blase, "El blanqueamiento como práctica racista en América Latina”, en Libro Anual del ISEE, México, Semaro, 2004, pp. 115-126.

${ }^{25}$ Laënnec Hurbon, El bárbaro imaginario, México, FCE, 1993, p. 15.

${ }^{26}$ Ibid., p. 58.

${ }^{27}$ Ibid., p. 89. 
Hurbon explica el modo en que la antropología haitiana decimonónica se encaminó a probar la aptitud de los negros para la civilización y refutar la definición del mundo negro como espacio ideal para el desarrollo de la tiranía, del canibalismo y de la superstición. Con todo, los intelectuales de aquella época, obsesionados por la problemática racial, cayeron en una especie de "racismo al revés", al plantear que la transplantación del pueblo negro a tierras más benignas, hizo que se abandonaran prácticas tenidas como bárbaras —el vudú y la lengua criollallegando inclusive a afirmar que Haití sería la "Francia negra". En cierto modo, tanto los intelectuales haitianos como los europeos sostuvieron la misma postura: la aparente conexión entre cambio físico y cambio moral. En este sentido, resulta claro que la propuesta de un mestizaje total se inserta en un mismo discurso: el racista. Como dice Hurbon, el primer momento de la nación haitiana está orientado por el discurso del mulato, "que se hace pasar por primo del amo (blanco) y por su legítimo sucesor al poder." Interiorizado el prejuicio de la superioridad racial de los europeos al tiempo que defiende la "civilización negra", el mulato se proclama como heredero espiritual del antiguo amo. Desde el Estado, se trabaja por la superación de la alienación cultural, lingüística y política, y se recurre a fetiches (como los libros) para combatir la alienación en que viven los haitianos creolófonos, monolingües, analfabetos y pobres. ${ }^{28}$

El racismo, desde luego, no es sólo la discriminación contra el negro, sino también contra el indio. Y, en realidad, contra cualquiera que escatime el valor supremo del mestizaje, base de la Nación. El Ecuador es un variopinto mundo mestizo en el que es posible encontrar diversos grupos cuya identidad es muy fluida: longos, cholos, chagras, chazos, montuvios, mulatos, zambos, pupos y blanqueados. Cada una de estas categorías, dice Valarezo, es ambigua. En algunos contextos hay quienes se identifican con alguna de estas categorías, pero en otros es un calificativo peyorativo para desvalorizarlos. El término "cholo" es aplicado por un gran sector del país a los indígenas que se convierten en mestizos, sobre 
todo cuando van a la ciudad; aunque los artesanos de origen mestizo, de larga tradición en la ciudad, son considerados cholos por los grupos dominantes y varios de ellos se identifican como tales. El "chagra", que es un campesino mestizo, cuando ingresa al mundo urbano pasa a ser conceptuado como "cholo". Así, afirma el autor, "cholo" es un término ambiguo y dinámico que tiene connotaciones étnicas, pero también clasistas, incorpora aspectos de marginalidad urbana y formas peyorativas de los de arriba para diferenciarse de lo popular urbano. La expresión "longo", otra de las categorías utilizadas para referirse a este sector, es utilizado en el mundo indígena para referirse con cariño a un o una joven, pero en el mundo mestizo es utilizado de manera despectiva para referirse a indígenas así como a mestizos populares. Otro término, "montuvio", tiene también una gran ambigüedad, ya que es utilizado como elemento de identidad tanto por los indígenas como por los campesinos mestizos manabitas, y en general por varios ecuatorianos para referirse al sector rural costeño. El vocablo "chagra" ha sido utilizado en la sierra para referirse a los mestizos de origen rural y pueblerino, sin embargo, recientemente se ha querido reivindicar lo "chagra" en los pueblos, en las corridas de toros populares y en las demostraciones de los jinetes a caballo. Las voces "pupo" en Carchi, "chazo" en Azuay y Loja, tienen resonancias similares a las del "chagra", aunque también pueden ser usados en su connotación étnica y clasista. ${ }^{29}$

También Perú, como Brasil y Ecuador, es paradigmático: la multiplicidad de rostros y la terquedad criolla por delimitar parece venir desde tiempos de la Colonia. En el Perú la relación entre mestizos (que pretenden ser, si no europeos, al menos criollos) y los otros, configura los estereotipos de los diversos segmentos que conforman tan multicultural sociedad, a pesar de los intentos institucionales de reformas del Estado hacia la consecución de una supuesta mayor democratización. Ya Mariá-

${ }^{29}$ Galo Román Valarezo, "El racismo en el Ecuador ensaya sus cantos”, RIMAY, año 2, núm. 13, Instituto Científico de Culturas Indígenas, Quito, abril, 2000. Disponible en: http://icci.nativeweb.org/boletin/abril2000/ramon.html. 
tegui remarcaría que las raíces de este problema, la superposición de elementos extranjeros combinados, insuficientemente aclimatados, está en el hecho de que el Perú es un Perú hijo de la conquista. Tanto los fazendeiros en el Brasil como los gamonales en el Perú, no dejan de ser las características más coloniales de estos países sudamericanos, que en lugar de promover el uso de nuevas formas de energía y tecnologías y el establecimiento de nuevas relaciones sociales de producción fueron el apéndice del antiguo sistema colonial y esclavista lusitano y español. A juicio de Guillermo Nugent es posible reconocer en dos tipos de líneas el modo de asumir una realidad multicultural como lo es la peruana. Las líneas que Pizarro trazó en la arena, - en aquella famosa escena de "Los trece del Gallo"- ${ }^{30}$ y las líneas de Nazca definen de manera muy nítida las separaciones hechas desde el régimen colonial para el cual, como es el caso de todos los imperios, es preciso marcar los límites, "pintar la raya" como se suele decir, como defensa ante el caos y la confusión. Las de Nazca, dice Nugent, son enormes y sin embargo no aplastan ni hacen diminutos a los hombres, pues apenas si se levantan algo sobre el nivel del suelo: no son líneas de demarcación, sino un conjunto de diseños, y por eso mismo exigen grandes esfuerzos para entenderlas. Pero sucede que el espacio peruano se organiza, desde que Pizarro "pintó su raya", en sentidos binarios: arriba/ abajo, sierra/ costa, andino/ criollo, jerarquías las más de las veces humillantes porque definen comportamientos sociales altamente diferenciados y diferenciadores en un ordenamiento que exhibe notables distorsiones de la realidad. ${ }^{31}$

Manos y sangres han tejido socio-culturalmente al peruano. Pero, colectivamente, no se imagina las relaciones de producción de otro modo del como son en la actualidad: algunos tienen profesiones, otros tienen trabajo y muchos más, tienen sólo oficios. En realidad, tanta diversidad (cultural y socioeconómica) produce un gran miedo. Y el temor, que es

${ }^{30}$ En la isla del Gallo, Pizarro trazó la línea divisoria entre los trece, que lo acompañaron a la conquista del Perú y lo decidieron regresar a Panamá.

${ }^{31}$ Guillermo Nugent, El poder delgado. Fusiones, lejanías y cercanías en el diseño cultural peruano, Lima, Fundación Friedrich Ebert, 1996, pp. 16-20. 
causa de muchos males, surge de un sentimiento de culpa, de una mala conciencia en relación a los prejuicios coloniales sobre los cuales, a pesar de lo humillantes que son, descansan los privilegios: "El rumor o el temor generan un eco interior duradero en la medida en que se asocia con una culpa subyacente a la que los sectores medios llegan a través de la conciencia del contraste entre ética y realidad". ${ }^{32}$ Adams, un psicoanalista norteamericano que ha trabajado sobre el tema de las relaciones entre inconsciente y multiculturalismo, señala que la "raza" (o, mejor aún, el "color") lo mismo que el sexo o cualquier otro contenido del inconsciente, es de suma importancia en el trabajo psicoanalítico. Asevera que hay que confrontar las actitudes inconscientes que bloquean el camino de auténticas relaciones multiculturales. ${ }^{33}$ Según él, los conflictos raciales vividos por el sujeto durante su sueño, no solamente sirven para desviar su atención de los problemas de orden sexual, como diría la tradición freudiana, sino que también puede referir a problemas igualmente vitales como los que conciernen a la vida política y social y que se expresarían mediante los arquetipos y estereotipos. ${ }^{34}$ En el Perú todos están tipificados: el indio tonto, el negro violador, el blanco pituco, el cholo arribista, etc. Estos estereotipos no siempre salen a la luz, sino que, como dice Callirgos, se manifiestan de manera implícita en chistes o insultos o bien de manera más abierta en los medios de comunicación (desde la TV hasta los graffiti callejeros). Si el síntoma neurótico puede expresar un conflicto entre fuerzas internas, el chiste, dice nuestro autor, puede expresar un conflicto entre fuerzas sociales. Es más, el conflicto puede ir más lejos cuando choca con ese discurso democratizador, sobre todo en un país con tan amplio espectro étnico y racial como es el caso de Perú, donde los rasgos raciales pueden ser considerados símbolos de poder e indicadores de pertenencia a clases sociales:

${ }^{32}$ Gonzalo Portocarrero, Racismo y mestizaje, Lima, SUR, 1993, p. 108.

${ }^{33}$ Michael Vannoy Adams, The multicultural imaginations: race, color and the unconscious, Londres, Routledge, 1996 p. 38.

${ }^{34}$ Ibid., p. 41. 
El peruano siente ese conflicto y lo vive dentro de sí; en algunos casos lo desplaza, en otros puede significar un trauma que lo afecte en su accionar diario. La raza puede ser un estigma: el blanco puede sentirse mal por serlo, porque a su apariencia están ligadas las imágenes de clase alta, de abusivo etc., que pueden generar sentimientos de culpa. El indio porque a su apariencia se ligan las imágenes de menor prestigio, ignorancia, incapacidad mental etc. Así, podríamos seguir con los otros grupos raciales. ${ }^{35}$

En el imaginario limeño la configuración social se ha tejido de manera especial: Perú es selva y sierra, regiones en muchas ocasiones supeditadas a la costa privilegiada y a la criolla Lima. Por supuesto no está de más recordar que la capital de Perú no fue edificada sobre la antigua capital del Tahuantinsuyo, sino en contraposición a ésta. Y Lima, bautizada Ciudad de los Reyes, "debe ser" tan blanca como sea posible, pues sería aquella blancura sinónimo de la élite, que desde la costa heredera de España, controlaría y absorbería lo que a su entender es fragmentador y dislocador. Ésta es una afirmación casi generalizada por quienes habitan barrios residenciales como San Isidro o Miraflores o Barranco y que se sienten amenazados por los migrantes que desde los años cuarenta llegan hacia Lima y otras ciudades importantes. Estos migrantes no conservarán su cultura intacta, sino que vendrán a modificar el rostro de Lima al redefinir el espacio urbano de otra manera y, en el contexto político, a generar nuevas opciones ideológicas urbanas. No es que existan solamente barrios venidos a menos (como en el caso de los tugurios o barrios decadentes), sino que además se crean barriadas o pueblos jóvenes que además de la novedad y el pluralismo cultural que se manifiesta en ellos, tienen por mayor característica la pobreza, fenómeno que ha modificado la identidad latinoamericana de manera drástica, especialmente la de las ciudades. ${ }^{36}$ En efecto, los movimientos migratorios han convertido a las ciudades en la expresión de la pluralidad cultural y étnica.

${ }^{35}$ Callirgos, op. cit., p. 161.

${ }^{36}$ Guillermo Nugent, El laberinto de la choledad, Lima, Fundación Friedrich Ebert, 1992 , p. 30. 
Es en la ciudad donde se asiste a la interpenetración de poblaciones y formas de vida dispares en el espacio de las principales áreas metropolitanas del mundo. Lo global se localiza, de forma socialmente segmentada y espacialmente segregada, mediante los desplazamientos humanos provocados por la destrucción de viejas formas productivas y la creación de nuevos centros de actividad. La diferenciación territorial de los dos procesos, el de creación y el de destrucción, incrementa el desarrollo desigual entre regiones y entre países, e introduce una diversidad creciente en la estructura social urbana, que en muchas ocasiones genera gran confusión. ${ }^{37}$

La única salida a esta desorganización e imprecisión es nuevamente la de "pintar la raya" y en estos días de documentos y de números de identificación, el papel asegura la inmovilidad social de quienes no los tienen. Debemos además cargar con una gran cantidad de ellos, pues aunque sean de tamaño portátil no somos nada sin un documento. Un papel sirve para recibir un pago, otro papel sirve para identificarse, uno más para comprobar el estado civil, otro más para demostrar la propiedad, en fin, siempre el "papelito que habla". Y no se trata sólo del papel que identifica, sino de la escritura vinculada al poder. En pocas palabras, y ése es el discurso de Nugent, no tener un papelito es vivir fuera de lo conocido, entre tinieblas, muy lejos de los otros, con los cuales ya no hay posibilidad de comunicación mientras no se busque lo que dice, lo que está escrito que dice la Mamá Ley: el "poder delgado", el poder escrito y comandando desde un delgado papel. ${ }^{38} \mathrm{El}$ problema aparece más crudo cuando se pretende vivir teniendo cerca a los que vivían lejos: esos, aquellos, los otros, los que no son "ni leídos ni escribidos", los que no entienden, los que, finalmente, tienen un modo de comunicación diferente y por ello peligroso desde una perspectiva logocéntrica de la tinta y el papel, herencia del cesarismo hispanista. En ese orden de ideas, Melgar escribe:

${ }^{37}$ Véase Jordi Borja y Manuel Castells, La ciudad multicultural, Madrid, Taurus, 1997.

${ }^{38}$ Nugent, El poder delgado..., pp. 35-36. 
La ciudad de Lima, de los años cincuenta, difícilmente podía seguir manteniéndose bajo el paradigma del criollismo, que había entrado en una fase crítica, al ritmo de su expansión urbana y recomposición cultural. La generación limeña nacida con el siglo se convirtió en la celosa reproductora de la memoria y la identidad criolla, pero cada vez con menos audiencia en las nuevas generaciones. Los que por esos años éramos todavía escolares de nivel primario, no podemos dejar de recordar los intentos infructuosos de los abuelos por impregnarnos de esa ideología romántica y filo-hispanista acerca de los criollos de la Lima Virreinal. ${ }^{39}$

Callirgos tampoco duda en afirmar que esta situación toma un cariz más fuerte con la migración del campo hacia Lima, y que va amenazando las minicorporaciones que resultaban de la estratificación de Perú, haciendo del choleo un elemento fundamental para la jerarquización: "El estereotipo del cholo cambia con la masiva migración a Lima: antes era visto como servil y destinado al servicio doméstico, ahora como 'acriollado', ambicioso, arribista. En los hogares de las clases altas se lamentan de que cada vez sea más difícil conseguir empleados domésticos que sepan quedarse en su lugar. Se pasa de la compasión [...] al franco insulto: cholo de m..., o a la visión de un ser resentido". ${ }^{40}$ A la clasista (e implícitamente racista) pregunta con relación al cholo, al indio o mestizo que se ha excedido, que ha invadido los espacios "blancos", que los ha "ensuciado" y que amenaza al no respetar las barreras, las demarcaciones y líneas divisorias, habría que considerar entonces otra más que le hace antesala al llamado "proceso de cholificación": la migración del campo a la ciudad que provocó la creación de una cultura chola, que hizo pensar a Quijano en la existencia de una identidad particular, la choledad. ${ }^{41}$ También Nugent, recordando el clásico texto que Paz presen-

${ }^{39}$ Ricardo Melgar, "El imaginario político y la identidad: los nacionalismos mestizos en el Perú. 1948-1960”, en Ricardo Melgar y Teresa Bosque [comps.], Perú contemporáneo: el espejo de las identidades, México, CCYDEL-UnAm, 1993, p. 204.

${ }^{40}$ Callirgos, op. cit., p. 174.

${ }^{41}$ Véase Aníbal Quijano, Dominación y cultura: lo cholo y el conflicto cultural en el Perú, Lima, Mosca Azul, 1980. 
tara en 1950, escribió El laberinto de la choledad pensando en una nueva cultura que combine, aunque no coherentemente, lo indígena con lo occidental e, incluso, en una ciudadanía chola. El masivo proceso de migración y empobrecimiento, que son para Nugent el nuevo horizonte social, todo lo pusieron de cabeza y es por ello que la diversidad se ha entendido más como fragmentación, ruptura, desintegración. Todavía hoy es casi imposible ver algún intento de fomento a una cultura pluriétnica y plurirracial y sí en cambio la recuperación del patrimonio histórico para deleite de los acriollados y a costa de quienes han sido desalojados del centro de Lima. De todas formas, la apuesta de Nugent por una ciudadanía chola implica un voto a favor de la pluralidad manifestada precisamente por los migrantes. Éstos se rediseñan y vuelven a diseñar la ciudad y por eso mismo apelan a una nueva noción de justicia, elaborada para ser dirigida hacia el respeto a todos, y la anulación de la justicia entendida desde un horizonte colonial en el que los que no son "ni chicha ni limonada" deben seguir a las órdenes de quienes sí tienen un lugar. La propuesta de Nugent va encaminada a dar un peso político a la imagen del cholo como imagen que permite dar sentido al descentramiento. El cholo puede ir hacia arriba o hacia abajo: es el representante de la movilidad social, pero es también a su vez el que no ha tomado en sus manos nuevas formas políticas de acceso a la participación y a la acción social. Nugent, siguiendo a Paz, apuesta también por la figura del laberinto como la imagen más apropiada para definir el espacio social, en este caso el peruano. ${ }^{42}$ De manera monstruosamente paradójica, por seguir la fórmula de Nugent, se desalojó a los indígenas y se les despreció, queriendo con ello destruir la imagen del laberinto para plantear más bien la de un edificio piramidal, cuya cúspide no podría ser objeto de invasión y mucho menos de ciudadanía obtenida por vías alternas al abolengo. En el momento en que se choleó el Perú cayó la fantasía de la Arcadia colonial. Por eso:

${ }^{42}$ Nugent, El laberinto de la choledad..., p. 18. 
Nos parece importante introducir una denominación para una forma específica de práctica discriminatoria; la denominación es choleo y se refiere a la discriminación ejercida sobre alguien considerado racialmente como inferior debido a sus antecedentes indios, pero que es evaluado también en función de aspectos socioeconómicos, educativos-lingüísticos y de la condición de migrante. No es sólo que la plata o el título universitario blanqueen - con cierto límite - sino que la pobreza o el lugar de origen también cholean [...] En otras palabras, para quien ejerce un juicio en relación al tema, un cholo es alguien a quien considera un inferior racial pero para saber quién es un cholo, consciente o inconscientemente, ese alguien usa criterios que no son siempre y solamente raciales. ${ }^{43}$

El choleo genera sentimientos confusos: no se quiere que el cholo forme parte de la gran familia peruana porque implicaría la fusión y la interconexión de los segmentos poblacionales y el peligro de perder "la pureza de la sangre". Afirma pues Nugent que: "renunciar a las jerarquías, por más humillantes y empequeñecedoras que resulten, implica el riesgo horroroso de la orfandad, de la disolución, de no ser siquiera menos que los demás. Catástrofe sin catarsis". ${ }^{44}$

En México, el naco es también alguien fuera de lugar, pues está en donde "no le corresponde", y vive al margen del tiempo ya que todo lo posterga. El ser y el estar del naco incomodan. La naquez, categoría que semánticamente llama a lo que debe ser tratado con desdén, cumple fines ideológicos. El naco es, por su rusticidad, un extranjero en la ciudad que paulatinamente rompe ataduras con su perfil particular, y por eso:

El naco no está en su sitio. Viene de otra parte. Para escapar de la pobreza abandonó el campo o alguna pequeña ciudad rezagada - la de su nacimiento. Acaso no inició él la marcha, sino sus padres, sus tíos, los parientes que lo arrancaron del paisaje originario. Es lo mismo. Haber llegado el mes anterior o hace veinte años, apenas altera las consecuencias del transplante. Como quiera que fuese, en los adentros del personaje habrá ocurrido una transmu-

${ }^{43}$ Walter Twanama, "Cholear en Lima”, Márgenes: encuentro y debate, año V, núm. 9, SUR, Casa de Estudios del Socialismo, Lima, octubre, 1992, p. 221.

${ }^{44}$ Nugent, El poder delgado..., p. 21. 
tación. Lo de menos es la ropa que se echa encima, con letreros de universidades yanquis o números grandes, como de jugador de fútbol americano. Lo de menos su gusto por el rock, el maltrato a la lengua materna y el olvido de la finura. La transformación no va por ahí. Cala mucho más abajo y adopta modalidades sutiles. ${ }^{45}$

Ser tipificado de naco, en el imaginario simbólico mexicano, resulta complejo, pues al término van asociados otros calificativos clasistas etnoculturales: negación, torpeza. El naco es, en suma, un ser "despreciable y oscuro" que ridiculiza, por ser él mismo "ridículo", los avances de la tecnología y la complejidad de todas las relaciones sociales. Además, tiene la "culpa" de su ridiculez. Aparece entonces lo que Ribeiro llamó el dilema latinoamericano: entre el genocidio y la insurgencia. El dilema en sí no es de carácter coyuntural, sino propiamente estructural en el sentido de que el sistema no ha sido capaz de absorber las masas marginadas e incorporarlas al mercado de trabajo tanto rural como urbano: "Como esta incapacidad conlleva el riesgo de que aquellas mismas simples aspiraciones activen a los marginados para subvertir un sistema que los excluye, las clases dominantes pasan a mirarlas con sospecha. Lo que temen es esta amenaza de irrupción violenta, porque saben que es imposible integrar las masas marginadas a la sociedad sin alterar sustancialmente la estructura de poder y la estratificación social". ${ }^{46}$ En todo caso, como afirman Ribeiro y Callirgos, resulta evidente que no pueden resolverse conflictos de clases si no se resuelven conflictos raciales que acarrean incomunicación en sociedades multiculturales: "La desintegración, el desencuentro social, es quizá el problema más grave del país. El que impide la construcción de consensos y de un proyecto nacional democrático, basado en el respeto por la vida y en la justicia". ${ }^{47}$

${ }^{45}$ Salvador Reyes Nevares, "Naquez y dependencia", en América Latina: historia y destino. Homenaje a Leopoldo Zea, México, UnAm 1992, t. I, p.159.

${ }^{46}$ Darcy Ribeiro, El dilema de América Latina: estructuras de poder y fuerzas insurgentes, México, Siglo XxI Editores, 1988, p. 104.

${ }^{47}$ Callirgos, op. cit., p. 213. 
Finalmente, podemos concluir que sí el racismo en América Latina es fundamentalmente un racismo colonial, y que la "limpieza de sangre" sigue siendo una obsesión. ${ }^{48} \mathrm{Si}$ en sus inicios, el mestizaje estuvo caracterizado por la bastardía, con la consolidación de los estados latinoamericanos los no-mestizos fueron considerados como los "ilegítimos". Hoy, sin embargo, se escuchan cada vez más fuerte las voces que afirman que si bien es necesario un "trasfondo melódico común", 49 también es necesario hacer espacio al ruido, a la disonancia. Sólo así podremos superar los prejuicios y las prácticas discriminatorias y acabar con los modelos neocoloniales.

Recibido: noviembre de 2006 Aceptado: marzo de 2007

${ }^{48}$ Nelson Manrique, "Algunas reflexiones sobre el colonialismo, el racismo y la cuestión nacional”. En: http://www.andes.missouri.edu/andes/especiales/nmpielypluma/nm_ pielypluma1.html.

${ }^{49}$ Véase Adela Cortina, La ética de la sociedad civil, Madrid, Anaya, 1994. 